\title{
COMPLEXO FERROVIÁRIO DE MARTINÓPOLIS - SP - UM PARTIMÔNIO NO CENTRO DA CIDADE
}

Mayara Pissutti Albano, Natália de Souza Sá, Sibila Corral de Arêa Leão Honda

Universidade do Oeste Paulista - UNOESTE, Curso de Arquitetura e Urbanismo, Presidente Prudente, SP. E-mail: sibila@unoeste.br

\section{RESUMO}

A expansão da estrada de Ferro no Estado de São Paulo, ocorrida em meados do século XIX, foi muito importante para a expansão da produção cafeeira, e para a colonização no interior do estado. A cidade de Martinópolis, teve sua fundação apoiada na chegada da Estrada de Ferro Sorocabana, sendo a ferrovia, por muito tempo, o principal fator de desenvolvimento econômico e social da cidade. Com o passar do tempo, um intenso processo de desestruturação do setor, acarretou no abandono e no sucateamento da malha ferroviária paulista. A partir desse pano de fundo, o presente artigo objetiva levantar a situação do complexo ferroviário de Martinópolis, verificando a situação do edifício da estação, os barracões, a linha férrea e seu entorno, fazer um levantamento histórico e fotográfico do local, ilustrando a situação vigente, destacando as potencialidades desse espaço no contexto do centro urbano. Pesquisas bibliográficas, documentais e in locu embasam o trabalho.

Palavras-chave: Estrada de Ferro Sorocabana, Patrimônio Ferroviário, Martinópolis, Urbanização, Centro Urbano.

\section{THE RAILROAD TRACK OF MARTINOPOLIS - SP - A CULTURAL HERITAGE DOWNTOWN}

\section{ABSTRACT}

The ralroad spread in São Paulo state, has happened at the end of 19th century, was really important to the spread of coffee field, and to the countryside settlement. The city called Martinopolis, was founded based on Sorocabana railroad, that was, for a long time, the main way to the cultural and social development of the city. Later on, with a deep process of destructuring, the railroad was scrapped and got left behind. Based on this backdrop, the aim of this article is to show the present situation of railroad track in Martinopolis, verifying the situation of railroad station, the sheds, the railway line and surrounding area, to do an area historical and photo surveying, illustrating the present situation, pointing out the potential of this area placed in the urban context. Bibliografical and document search, in locu lay the foundation of the essay.

Keywords: Sorocabana Railroad Track, Railroad Heritage, Martinopolis, Urbanization, Urban Center. 


\section{INTRODUÇÃO}

A expansão da estrada de Ferro no Estado de São Paulo, que ocorreu na segunda metade do século XIX, foi de extrema importância para o rompimento das barreiras espaciais da produção cafeeira, que evitavam a economia se expandir para o interior do estado. A cidade de Martinópolis se localiza no oeste do estado, teve sua fundação apoiada na chegada da Estrada de Ferro Sorocabana, assim como diversas cidades da região. Durante muito tempo a ferrovia foi o principal fator de desenvolvimento econômico e social da cidade, porque era através da estação que embarcavam e desembarcavam pessoas e mercadorias (DALTOZO, 1999).

Com o passar do tempo, a chegada da crise da economia agrícola e o avanço da industrialização, o transporte rodoviário, através do uso de caminhões, passou a ser o principal meio de integração regional, função que a ferrovia não conseguiu cumprir. Assim, começou um intenso processo de desestruturação do setor, que acarretou o abandono e no sucateamento da malha ferroviária paulista já observado no final da década de 1980 (MARQUES, 2009).

Atualmente é comum encontrar o complexo ferroviário de muitas cidades abandonados, em desuso, subutilizados, com o percurso da linha férrea abandonada, tornando-se barreira urbana, local de uso de drogas, trazendo inúmeros prejuízos às cidades, ilustrando o descaso, muitas vezes, com elementos que deveriam ser preservados, visto que são importantes símbolos da história e do desenvolvimento da região.

Portanto, o presente trabalho objetiva levantar a situação do complexo ferroviário de Martinópolis - SP, verificando a situação do edifício da estação, os barracões, a linha férrea e seu entorno. Também visa a fazer um levantamento histórico e fotográfico do local, ilustrando a situação vigente, e destacar as potencialidades desse espaço no contexto urbano.

\section{METODOLOGIA}

As pesquisas foram embasadas em levantamentos bibliográficos, buscando um aprofundamento teórico do tema, numa segunda fase, foram realizadas pesquisas documentais e levantamentos físicos territoriais in locu.

\section{COMPLEXO FERROVIÁRIO E MARTINÓPOLIS - SP}

Martinópolis está localizada na região do Oeste do Estado de São Paulo, possui 24.219 habitantes, (IBGE, 2015). A cidade teve início em medos do século XIX, quando sertanistas mineiros 
buscavam riqueza, poder e novas terras, desbravando a área entre o rio do Peixe e rio Paranapanema. Esses senhores se tornaram proprietários de latifúndios distintos que se estendiam desde Campos Novos do Paranapanema até as barrancas do Rio Paraná, e seguiram desafiando a floresta inóspita e os índios Coroados, Caiuás e Chavantes, travando com eles grandes lutas sangrentas dizimando famílias de índios e outros pioneiros para então ocupar o solo (DALTOZO, 1999).

Com a descoberta dessas terras vindouras, o Governo passou atrair-se por essa região, com isso houve o início da construção da estrada boiadeira, que ligava o mercado produtor de gado (Mato Grosso) ao mercado consumidor (São Paulo), sendo utilizada por fazendeiros principalmente matogrossenses, que pagavam taxas para transitar por ela. A referida estrada atravessava os campos do Laranja Doce e seguia em direção a Indiana, transformando-a na primeira grande fazenda de criação de gado da região (DALTOZO, 1999).

O café era a maior atividade econômica do Estado de São Paulo no início do século XIX. Devido a sua constante expansão, necessidade de novas terras para seu cultivo, chegou por volta de 1820, no Vale do Paraíba, e algum tempo depois já estava presente em todas as regiões do estado. Com isso, segundo o website da Prefeitura de Martinópolis, fez-se necessário um meio de transporte para escoar essa mercadoria para seus devidos fins, logo, fazendeiros financistas e exportadores se organizaram para a construção da estrada de Ferro Sorocabana, fundada por Luiz Matheus Maylasky em 02 de fevereiro de 1870.

Na manhã do dia 5 de agosto de 1917 foi inaugurada a estação de José Teodoro, atual Martinópolis (Figura 1), construída rapidamente de alvenaria para servir de plataforma. Os trilhos traziam colonizadores que adquiriram fazendas ao redor da estação para então lotear e vender às pessoas vindas de todo local, com o objetivo de adquirir seu pedaço de chão e desbravá-lo, conforme website da Prefeitura de Martinópolis.

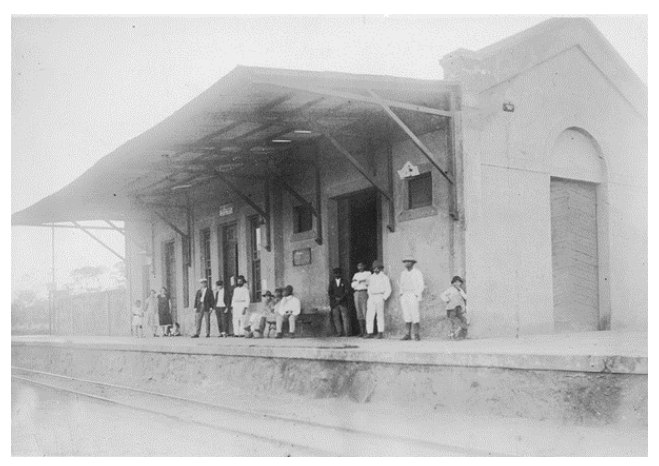

Figura 1. Estação Ferroviária de Martinópolis em 1917.

Fonte: Museu Virtual Martinópolis, 2015. 
O Coronel João Gomes Martins no dia 14 de novembro de 1924 comprou uma gleba, margeando a estação em direção ao Rio do Peixe. Com aquisição da mesma para erguer um povoado ao lado norte da estação, em poucos anos, a gleba foi se transformando e tomando feição de vilarejo (DALTOZO, 1999).

No dia 20 de dezembro de 1929, o povoado de José Teodoro foi elevado à categoria de Distrito de Paz, e dez anos depois conseguiu sua emancipação política. Sendo instalado oficialmente em 29 de janeiro de 1939, o então distrito de José Teodoro teve seu nome modificado para município de Martinópolis, em homenagem ao colonizador João Gomes Martins que havia falecido dois anos antes (DALTOZO, 2007).

Durante décadas a ferrovia foi o principal fator de desenvolvimento econômico e social da cidade, porque era na estação, que embarcavam e desembarcavam pessoas e mercadorias. Com o passar do tempo, a chegada da crise da economia agrícola e o avanço da industrialização, o transporte rodoviário, através do uso de caminhões, passou a ser o principal meio de integração regional, função que a ferrovia não conseguiu cumprir. Assim, começou um intenso processo de desestruturação do setor, que acarretou o abandono e no sucateamento da malha ferroviária paulista já observado no final da década de 1980 (MARQUES, 2009).

Ao analisar o local de estudo nota-se que o impacto sócioespacial da implantação da estação ferroviária na cidade de Martinópolis foi grande, graças a modernidade trazida por ela, que proporcionou grande avanço do comercio, e trouxe a possibilidade de pessoas e mercadorias transitarem de uma cidade a outra. Devido a isso assistiu-se uma alteração da sua paisagem, através da expansão de moradias ao norte da linha férrea, com intuito de abrigar pessoas que vinham morar e trabalhar na cidade.

Identificam-se elementos urbanos uma paisagem específica ao redor da linha férrea: a ferroviária, que conserva elementos da gênese da formação desses núcleos urbanos e, portanto, da memória [...], conformando uma "paisagem cultural". Um território com significado cultural que dá testemunho, ao passado e ao presente, do relacionamento existente entre os indivíduos e seu meio ambiente e ajuda a especificar culturas locais, práticas, sensibilidades, crenças e tradições (PASSARELLI, 2006 p.374).

A estação ferroviária que antes era utilizada como local de atração de pessoas e mercadorias, atualmente encontra-se com uso alterado e seu entorno em abandono e desuso ocasionado pela falta 
de interesses e incentivos públicos, e devido a novas formas de transportes evidenciados no mundo atual.

Vale dizer que o dever de cada cidadão e do poder público é preservar o saber brasileiro, evidenciando e valorizando, ao contrário de o anularem, seja através de fotos, de documentários, de registros, entre outros, deve-se guardar para amanhã informações relacionadas aos elementos culturais, que não há garantia duradoura (LEMOS, 2010).

A Estrada de Fero Sorocabana possui grande importância para as cidades do oeste paulista, e para Martinópolis, pois representa o veículo de desenvolvimento econômico, político e cultural, e foi no seu entorno que a o primeiro loteamento que deu início a cidade surgiu. Por esse motivo, são consideradas patrimônio histórico e cultural, simbolizando uma referência ao passado, e por isso é importante preservar sua memória (DUMCZUK e MONASTIRSKY, 2010).

Por se tratar de um local que faz referência ao passado, é um local merecedor de proteção. 0 ato de preservar faz com que lugares históricos, estilos arquitetônicos, artes tradicionais, festas, costumes e tradições não percam o seu valor e sejam repassados às gerações futuras (DEMCZUK e MONASTIRSKY, 2010). Logo é possível perceber a ligação entre o patrimônio cultural ferroviário e a identidade das localidades. Preservar, entretanto, não é sinônimo de estagnação e de perda de investimentos, é possível adaptar velhas construções e espaços urbanos para atividades atuais dandoas funções compatíveis, valorizando o imóvel e o entorno.

O complexo ferroviário de Martinópolis é composto pelos trilhos, dois galpões grandes e o edifício da estação. Esta região se localiza na área central do município (Figura 2), entre as Avenidas Cel. João Gomes Martins e Prof. Nilva, perpendiculares à Rua Nove de Júlio, a linha amarela tracejada representa a Estrada de Ferro Sorocabana; o retângulo vermelho representa a Área da Antiga Estação Ferroviária.

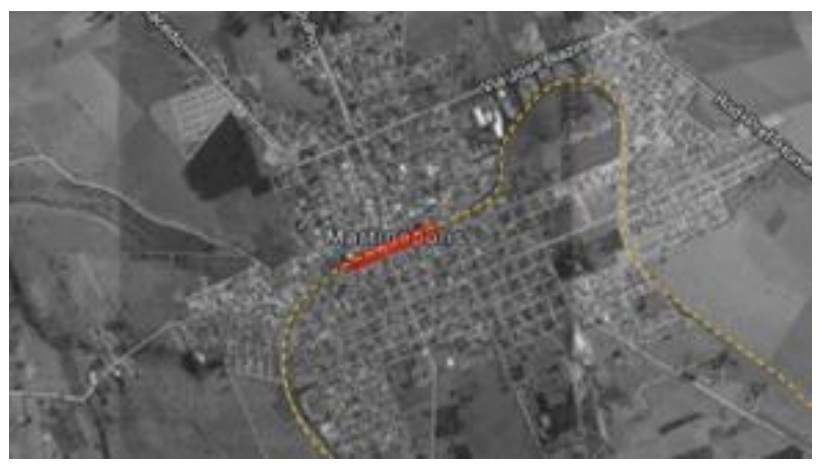

Figura 2. Situação da Estação Ferroviária e Estrada de Ferro na Malha Urbana de Martinópolis Fonte: Google Maps; Organização: Autoras, 2015. 
O entorno da antiga estação é muito importante, porque representa seus reflexos de desenvolvimento desde a sua fundação até os dias atuais. A estação está localizada no centro da cidade, há uma diversificação de usos, conforme pode-se observar na Figura 3.

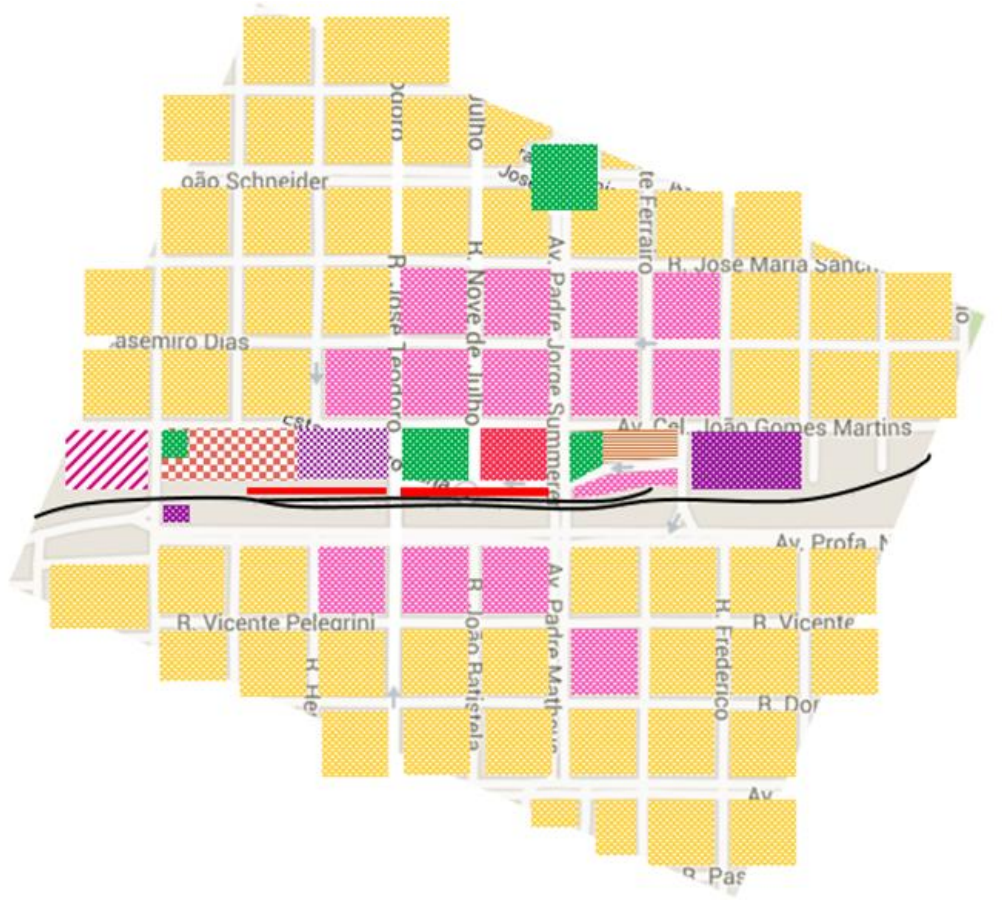

Praças Publicas

Área Residencial

Comercio

Posto de Saúde

Edifício Desativado

Prefeitura Municipal

Área de Esportes

Escola Infantil

Edifício Estação

Linha Férrea

Vazios

Rodoviária

Figura 3. Análise Gráfica da Setorização de Usos do Entorno da Estação Ferroviária de Martinópolis Fonte: Google Maps; Organização: Autoras, 2015.

Os edifícios do complexo ferroviário de Martinópolis foram alvo de recente reforma e abrigam projetos sociais da cidade (Figura 4). Os edifícios são de propriedade da União, que sede os mesmos para fins de sociabilização e aprendizagem, junto a memória da estação.
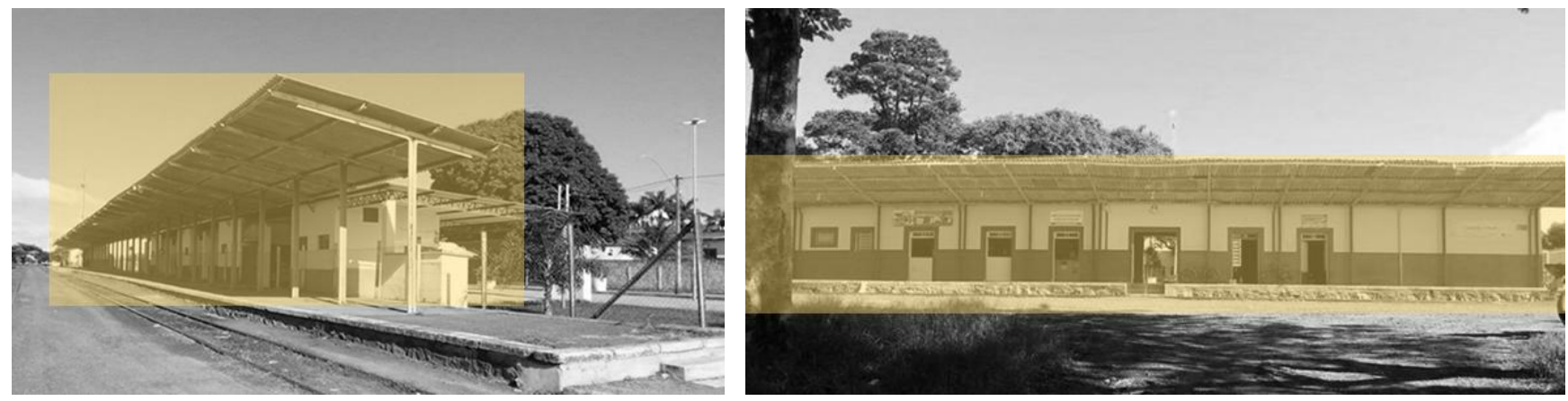

Figura 4. Edifício Principal, Estação Ferroviária de Martinópolis, ponto de parada do trem Fonte: Autoras, 2015. 
Na edificação principal onde é a Estação Ferroviária que foi tombada recentemente, se encontra a Biblioteca Municipal José de Alencar, com uma sala administrativa e banheiros, uma vitrine Museu com objetos de várias épocas que fez parte da história da cidade, uma sala destinada as voluntárias do Projeto Querer Bem e uma sala para as Artesãs.

Nos Galpões (Figura 5) funciona o Espaço Cidadão, que é um serviço de Convivência e Fortalecimento de Vínculos da Assistência Social. Que atende crianças e jovens com oficinas sócio educativas. Mesmo com divisões de ambientes os galpões são interligados entre si.

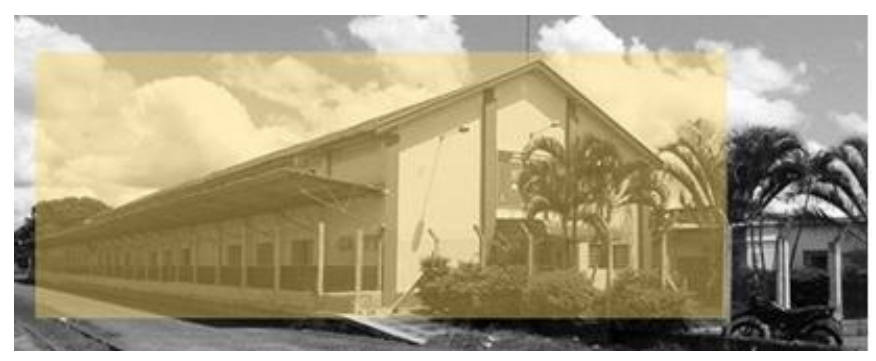

Figura 5. Galpão da Estação Ferroviária de Martinópolis Fonte: Autoras, 2015.

Já o percurso da linha férrea encontra-se sem uso, e reflete uma situação de abandono, visto que não possui calçamento (Figura 6 - a ), dificulta o acesso da população, que utiliza o espaço como passagem, e para aqueles que utilizam o espaço da estação e dos barracões, nas atividades oferecidas (Figura 6 - b).

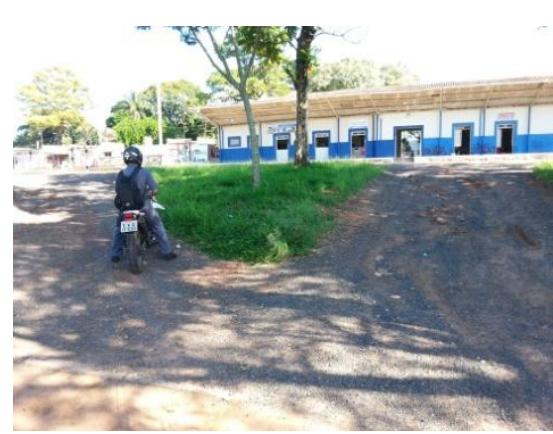

a

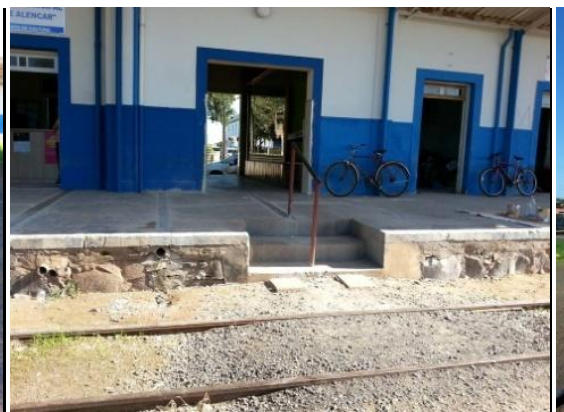

b

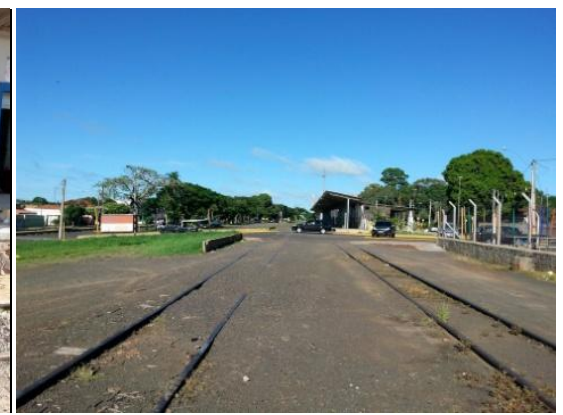

C

Figura 6. Linha férrea nos arredores da estação.

Fonte: Autoras, 2015. 
Logo se justifica uma intervenção no espaço, para que não se tenha no centro da cidade uma área ociosa e com configurações de abandono. Tal área, se remodelada poderia funcionar como uma área de lazer e descanso para população que trabalha ou frequenta o centro de Martinópolis, pois se trata de uma região da cidade, densamente ocupada, e uma área livre de lazer, instalada ao longo da linha férrea, poderia colaborar para a melhoria da qualidade de vida da população.

\section{CONSIDERAÇÕES FINAIS}

A área de estudos trata-se de uma área de extrema importância para a memória da cidade de Martinópolis - SP. O edifício da estação foi tombado, reformado recentemente e encontra-se com usos que beneficiam a população, bem como os barracões, que também se encontram em bom estado de conservação e são utilizados como espaço para cursos e oficinas de cunho social, configurando pontos positivos para a cidade, sua memória e para a vitalidade de um espaço tão importante.

O percurso da linha férrea, no entanto, não se encontra na mesma situação, conforme discutido no presente artigo. Não possui incentivos e condições para seu uso, resultando em sua ociosidade. É uma área com grande potencial, que poderia ser melhor aproveitado através de uma intervenção, transformando-a numa área de lazer, em um espaço densamente ocupado, colaborando para a melhora da qualidade de vida da população.

\section{REFERÊNCIAS}

DALTOZO, José Carlos. Martinópolis, sua História e sua Gente. Martinópolis (SP), Gráfica Martipel Ind. E Com. Ltda, 1999.

DEMCZUK, Paula G.; MONASTIRSKY, Leonel Brizolla. Ferrovia e memória: reflexões sobre a ferrovia em Irati-Pr e seu uso como produto turístico. In: Revista Discente Expressões Geográficas, n 6, ano VI, P. 71 - 89. Florianópolis, junho 2010.

LEMOS, Carlos A.C. O que é patrimônio histórico. 2. ed. ver. e ampl. São Paulo: Brasiliense, 2010. (Col. Primeiros Passos, 51).

MARQUES, P.P. Técnica, modernização e produção do espaço: um estudo sobre o papel da estrada de ferro nas transformações sócio-espaciais da Zona Alta Sorocabana. Dissertação de Mestrado Faculdade de Filosofia, Letras e Ciências Humanas. Universidade de São Paulo, São Paulo, 2009.

MARTINÓPOLIS, Histórico do Município de Martinópolis, 1927. Disponível em:http://www.martinopolis.sp.gov.br/site/index.php. Acesso: 10 março 2015. 
PASSARELLI, Silvia H. Facciolla. Paisagem ferroviária: memoria e identidade da metrópole paulistana. / Revista Exacta, - São Paulo, v. 4, n. 2, p. 373-383, jul./dez. 2006.

IBGE. Cidade de Martinópolis, $1939 . \quad$ Disponível em: http://cidades.ibge.gov.br/painel/painel.php?codmun=352920. Acesso: 03 abril 2015. 